\title{
La dimensión ética del desarrollo local
}

\section{The ethical dimension in the local development}

\author{
JULIO CASTELLANOS RODRÍGUEZ \\ Universidad de Matanzas. Cuba \\ Correo electrónico:julio.castellanos@umcc.cu
}

JUAN R. PENTON LÓPEZ

Universidad de Matanzas. Cuba.

Correo electrónico:juan.pentón@umcc.cu

ROBERTO A. FRÍAS JIMÉNEZ

Universidad de Matanzas. Cuba

Correo electrónico: roberto.frias@umcc.cu

RECIBIDO: 21 septiembre 2014 / APROBADO: 28 octubre 2014

\section{Resumen}

Las concepciones actuales sobre el desarrollo local tienen cierto enfoque tecnocrático al concebir solo la dimensión económica, ecológica y científica tecnológica vinculada a la gestión del conocimiento. Este criterio no reconoce el papel medular que desempeña la dimensión ético moral en el ámbito social. El propósito fundamental de este trabajo es realizar un enfoque crítico del problema, tal y como se presenta en la realidad cubana actual, partiendo de la concepción martiana y marxista en la obra cultural de la Revolución Cubana.

PALABRAS CLAVE: ética, desarrollo local, educación ético moral, factores de riesgo, raíces del pensamiento cubano 


\begin{abstract}
:
The nowadays conceptions about the community development, have a certain technocratic focus when conceiving just the economic, scientific, technic and environmental dimension bound to the knowledge management. This criteria doesn't recognize the central role that means the moral athics dimension in the social life. The aim of this research is to perform a critic analisis of the problem itself as it is showed in the nowadays Cuban society, beginning with Marti's and Marx's conception of the cultural development in the Cuban Revolution.
\end{abstract}

Keywords: ethics, community development, morals and ethis education, risk factors, roots of the Cuban way of thinking

CLASIFICACIÓN JEL: Z10, Z19.

\section{Introducción}

Asistimos a un intensivo y acrecentado deterioro de valores morales y cívicos, como la honestidad, la decencia, la vergüenza, el decoro, la honradez y la sensibilidad ante los problemas de los demás. Esta compleja problemática ético moral es de carácter internacional, nacional, comunitario, familiar e individual.

La problemática ética tiene carácter multicausal y multi-implicativo que demanda intervenciones integradas e interinstitucionales para comprender, explicar y transformar los diferentes factores de riesgo que favorecen y fortalecen el desarrollo de la misma. La familia, la escuela, y la sociedad en general, como instituciones en crisis, son los principales factores de riesgo que favorecen el deterioro ético.

En el desarrollo local y su dimensión ético moral de la sociedad cubana, ha sido insuficiente la comprensión del "juego mutuo de acciones y reacciones" (Engels, 1974) entre la vida material y espiritual, inherentes a la concepción dialéctica marxista de la sociedad como fundamento teórico- metodológico de análisis. En las concepciones actuales del problema, tampoco está concebida la dimensión ético moral, de profundas raíces cristianas, elaboradas y validadas por los precursores del pensamiento cubano y latinoamericano que se sintetizan en José Martí.

Factores de riesgo (Castro, 2013, 2014)

- Existen contradicciones de consenso frente al deterioro ético moral, tales como:

- La problemática moral, entendida como la pérdida de valores éticos y el irrespeto a las buenas costumbres no ha sido abordada mediante la acción concertada de todos los factores sociales, ni se ha tenido en cuenta el papel decisivo de la familia y la escuela como instituciones claves en la educación de todos los ciudadanos.

- El proceso revolucionario es símbolo de dignidad, independencia, humanismo e intransigencia en defensa de los principios; a pesar de ello, la corrupción es una de las manifestaciones de la degradación ético moral de la sociedad. 
- Las plataformas de pensamiento liberal y de restauración del capitalismo neocolonial enfiladas contra las esencias mismas de la Revolución Socialista, a partir de una manipulación premeditada de la historia, ha permeado una parte de la sociedad cubana de elementos del mercado que tienden a desarrollar una cultura de consumo y estimulan el individualismo, el egoísmo y el amor excesivo a la riqueza material en menoscabo de los valores, la identidad y la cultura nacionales.

- Se mantiene hoy el ambiente de indisciplina que se ha arraigado en nuestra sociedad y ocasiona daños morales y materiales nada despreciables, a pesar de los esfuerzos realizados sobre todo a partir del VI Congreso del PCC y de sus lineamientos y las directrices de la Conferencia del Partido.

- Es insuficiente el conocimiento y cumplimiento de los principios ético morales de la Constitución de la República de Cuba y, por tanto, de la misión del socialismo cubano plasmada en su preámbulo: En él se declara la voluntad de que la ley de leyes de la República este presidida por este profundo anhelo, al fin logrado de José Martí: "Yo quiero que la ley primera de nuestra República sea el culto de los cubanos a la dignidad plena del hombre" (Constitución de la República de Cuba, 1992)

- Se observa en la sociedad, cierto distanciamiento entre el discurso, matizado por arengas y consignas vacías, y la falta de ejemplo personal.

- Las decisiones políticas y económicas a menudo no tienen en cuenta los factores ético morales ni la imprescindible consulta con el pueblo, lo que genera incertidumbre y pesimismo y un ambiente de enajenación social justificado en el supuesto bien protegido del ejercicio de la democracia.

- En el ejercicio de la justicia se presenta la contradicción entre lo legal y lo moral.

- La información preventiva sobre el estado de la conducta ético moral es descalificada por la sobredosis de desinformación y sensacionalismo en los medios de comunicación.

- En el montaje de la sociedad han predominado, en la práctica, los criterios políticos económicos sobre los criterios éticos morales.

- Existe un desconcierto e interpretaciones erróneas en la proporcionalidad de los conceptos justicia, igualdad, y equidad, contentivos en las raíces de la concepción ética y humanista cubana, a partir de aberraciones producidas en la definición y aplicación del principio de distribución socialista (Marx, 1974) que da cumplimiento a la Ley de la distribución con arreglo al trabajo.

- La estructura social de la problemática ético moral está conformada por un conjunto de elementos que incluyen el pensamiento y el sistema de virtudes y la conducta de los hombres. La misma se presenta hoy como un fenómeno contradictorio, derivado de una realidad internacional mercantil en crisis y de aberraciones que se producen en el intento de construir la nueva sociedad.

- La modernidad y el desarrollo, concebidas solo desde el prisma neoliberal y mercantil, esconden profundos problemas ético morales que mantienen a muchas personas infelices por las falsas expectativas 
materiales y dependientes del consumo de los "nuevos valores" que permanentemente están afectando y extravían el rumbo de la familia, la comunidad y la sociedad.

- El consumismo, la desinformación y la pragmatización que predominan en el modo de vida actual, fortalecen y tienden a consolidar patrones de dependencia y búsqueda incesante de deslumbrantes e indiscretos encantos de la sociedad de consumo, surgidos del acceso a otra mentalidad, a nuevos tipos de comportamiento que conducen a una nueva concepción del mundo con enajenantes implicaciones en el orden espiritual. El crecimiento de la riqueza material es inversamente proporcional al desarrollo espiritual. Martí lo expresa: “... ¡Cuánta batalla ganada supone la riqueza! ¡Y cuanto decoro perdido!" (Martí, 1975).

- La educación cubana ha hecho el énfasis en el crecimiento de las cualidades inteligentes del hombre y ha descuidado el desarrollo de sus sentimientos como cuestión más esencial del mejoramiento humano, lo cual refleja la contradicción en un pueblo que es hoy cada vez más instruido pero no necesariamente más culto, que ha retrocedido, no solo en la cultura, sino también en el civismo ciudadano.

\section{Volver a las raíces}

En la actualidad, algunos cientistas y académicos cubanos vinculados a la educación, se inclinan y sugieren teorías filosóficas y sociológicas occidentales que se apartan de las más autenticas raíces del pensamiento cubano y latinoamericano, argumentando la necesidad de recurrir a un pensamiento mas actual, más moderno, puesto que muchas de las ideas originales, según ellos, son viejas o en desuso.

El doctor Armando Hart Dávalos, profundo estudioso de las ideas martianas y marxistas, defiende el criterio de Ernesto Che Guevara cuando escribe: "El Che señaló refiriéndose precisamente a las desviaciones que venían ocurriendo en el socialismo, que cuando un aviador pierde el rumbo, debe volver al punto de partida para recuperarlo..." (Hart, 2004)

En aspectos medulares de la educación ético moral, la sociedad cubana ha perdido el rumbo. Recuperarlo significa volver al punto de partida: las ideas originales de Marx, Lenin, Bolívar, Martí y toda la tradición del pensamiento filosófico y educativo cubano y latinoamericano. Un párrafo escrito por cualquiera de estos hombres en el siglo XIX, vale y educa más que diez libros actuales.

La dimensión ético moral del desarrollo local, forma parte del sistema de relaciones humanas que se integran y conforman la sociedad. La vida espiritual ha mostrado su existencia real y su notable incidencia práctica en los procesos revolucionarios del siglo XX y, como fenómenos culturales, nos confirman uno de los principios básicos formulado por José Martí en el siglo XIX: la guerra es de pensamiento. Ganar la guerra de pensamiento requiere una visión consistente en:

- Cambiar el diseño del enfrentamiento ideológico.

- Norehuiraldebate,ninegardogmáticamente los argumentos del adversario.

- Fundamentar la negación dialéctica en la teoría y en la práctica.

La síntesis crítico - metodológica, concebida en términos de moral universal, posibilita y fundamenta la originalidad de la Revolución Cubana, dada por la asimilación y apropiación del pensamiento científico marxista y martiano, a partir de la cultura espiritual de "Nuestra América", y del compromiso ético "con los pobres de la tierra". (Martí, 1997).

La producción intelectual de Carlos Marx, junto a la 
de José Martí, devienen en importante "guía para la acción" de hombres y pueblos:

- Por su valor potencial para la acción transformadora de la realidad social.

- Por ser fundamento de la cultura científico humanista

- Porque como síntesis creadora de pensamiento y acción, C. Marx nos legó el método revolucionario de estudio e investigación, J. Martí es la opción ético crítica.

La concepción dialéctica elaborada por Carlos Marx, que parte de la tesis de que el modo de producción de la vida material condiciona el proceso de la vida social política y espiritual en cualquier ámbito de la sociedad, fundamenta teórica y metodológicamente el problema ético moral del desarrollo local. Las relaciones de producción constituyen la estructura económica de la sociedad sobre la cual se levanta la superestructura jurídica y política y a la que corresponden determinadas formas de la conciencia social que, desde luego, incluye la moral.

En la interrelación de estos elementos es que Marx entiende las diversas épocas económicas. El estudio de Marx no es determinismo económico, sino dialéctica. Este es el aporte más trascendental que hace a las Ciencias Sociales que conserva actualidad dentro de los estudios sociológicos.

Después de la muerte de Marx, Engels se vio necesitado de criticar la interpretación que dieron los filósofos y economistas vulgares a la concepción marxista. En cartas escritas durante la década de los años 90 de siglo XIX a varios de sus amigos y adversarios, les plantea que en la concepción de Marx se evidencia un juego de acciones y reacciones que está muy lejos de un enfoque dogmático y determinista de la sociedad. El otro componente que fundamenta la dimensión ético moral del desarrollo local es el pensamiento de José Martí, síntesis del pensamiento cubano y latinoamericano, de profundas raíces éticas y cristianas. El mismo aporta elementos esenciales de la espiritualidad política, jurídica, cultural y moral a la sociedad cubana. Martí es la fuente principal de inspiración de la Revolución Cubana; posee un pensamiento humanista excepcional acompañado de un sistema de virtudes, una firmeza y una fuerza moral poco comunes.

El Apóstol tiene fe en la utilidad de la virtud y en el mejoramiento humano. No concibe una república fundada sobre otras bases. A su hijo escribe en Ismaelillo: "Hijo, espantado de todo me refugio en ti. Tengo fe en el mejoramiento humano, en la vida futura, en la utilidad de la virtud y en ti" (Martí, 1975), y en su artículo Variedades de París, señala: "En virtudes - solo sobre base de virtudes- se alzan pueblos respetables y nobles" (Martí, 1973, pág. 16) Martí vincula la virtud y su utilidad al cultivo del espíritu y la inteligencia de los seres humanos, a la generosidad, la ternura, la bondad y el decoro, la sencillez y la pureza, el amor al trabajo, la humildad, la amistad y solidaridad entre los hombres.

El artículo Maestros Ambulantes, (Martí, 1973, pág. 288), por ejemplo, es un manantial de ideas que se relacionan con la virtud y su utilidad. Las ideas principales que se pueden encontrar en esa obra son:

- La generosidad como práctica constante para conquistar la felicidad.

- La bondad, base de la dicha, la cultura y la libertad.

- El conocimiento científico y la ternura, base de la independencia, la bondad y el decoro.

La virtud y su utilidad están presentes en toda la obra del Apóstol, en cada palabra, en cada renglón, párrafo o fragmento de la misma y se refleja con especial énfasis en su epistolario. Las cartas escritas durante 
los últimos meses de su vida a las hermanas María y Carmita Mantilla, (Martí, 1975) son otro buen ejemplo donde se destaca el tratamiento de las virtudes del hombre. Los valores más trascendentales implícitos en estas cartas son:

- El amor como sentimiento más profundo del ser humano.

- El mérito y la pureza como virtudes

- El decoro y el estudio, bases del respeto a los demás.

- El trabajo virtuoso, base de la libertad y el mejoramiento humano.

- La educación a los demás para ser mejores seres humanos.

- El estudio de las ciencias y el enfoque científico del mundo.

- La contraposición de la honradez y la inteligencia a la belleza externa y la vanidad.

Derívese de los aspectos anteriores el fundamento ético moral de lo que pudiera ser una sociedad mejor.

\section{Conclusiones}

En los criterios actuales del desarrollo local, ha sido insuficiente la comprensión del "juego de acciones y reacciones" entre la vida material y espiritual de la sociedad que ofrece la concepción dialéctica de Marx. Se ha obviado, además, la fuente inagotable del pensamiento cubano y latinoamericano de profundas raíces éticas que se sintetizan en José Martí.

Un grupo de factores de riesgo han dañado sensiblemente aspectos medulares de la educación ético moral la sociedad cubana. Retomar el rumbo significa volver a las ideas originales de Marx, Lenin, Bolívar, Martí y toda la tradición del pensamiento filosófico y educativo cubano y latinoamericano.

\section{Referencias bibliográficas}

- Castro Ruz, R. (7 julio 2013). Intervención en la Primera Sesión Ordinaria de la VIII Legislatura de la Asamblea Nacional del Poder Popular. Palacio de Convenciones, Cuba.

- Castro Ruz, R. ( 21 diciembre 2013). Discurso en la clausura del Segundo Período Ordinario de Sesiones de la VIII Legislatura de la Asamblea Nacional del Poder Popular. Palacio de Convenciones. Cuba

- Castro Ruz, R. (1 enero 2014). Discurso en el acto de conmemoración del 55 Aniversario del triunfo de la Revolución. Parque Carlos Manuel de Céspedes. Santiago de Cuba

- Constitución de la República de Cuba. (1992). Editora Política, Ciudad de La Habana, Cuba, pág. 3

- Engels, F. (21-22 septiembre 1890). Engels a Joseph Bloch.

- Marx,C. y Engels,F.(1974). Obras Escogidas, Tomo 3. Moscú: Editorial Progreso.

- Hart, A. (2004). ¿Cuál es el verdadero pensamiento de Marx y Engels? Revista Cuba Socialista No.31, Revista Trimestral editada por el Comité Central del Partido Comunista de Cuba, Tercera época No.31.

- Martí, J. (1975). Obras Completas, Tomo VIII. La Habana: Editorial Ciencias Sociales, pág.161

- Martí, J. (1977). Odio la máscara y vicio. Versos sencillos, Cuadernos martianos II Secundaria Básica, Selección de Cintio Vitier. La Habana: Editorial Pueblo y Educación. pág. 71

- Martí, J. (1975). Ismaelillo, OC t 16. La Habana: Editorial Ciencias Sociales, pág. 17.

- Martí, J. (1973). OC, t 28. La Habana: Ciencias Sociales, pág. 16.

- Martí, J. (1973). OC, t 8. La Habana: Ciencias Sociales, pág. 288

- Marx, C. (1974) Crítica al Programa de Gotha, C. Marx, F. Engels, Obras Escogidas en tres tomos, T. 3. Moscú: Editorial Progreso, Moscú, pág. 12-15 